\title{
EDUCAÇÃO DE QUALIDADE: UM DOS DILEMAS FUNDAMENTAIS PARA A DEFINIÇÃO DAS POLÍTICAS EDUCATIVAS
}

\author{
EDUCATION OF QUALITY: ONE OF THE FUNDAMENTAL DILEMMAS FOR THE DEFINITON OF \\ EDUCATIONAL POLICIES
}

Roberto Gerardo Bianchetti ${ }^{1}$

Resumo 'Educação de qualidade' e 'qualidade da educação' são termos repetidos nos documentos e discursos que acompanham as propostas de ação no terreno educativo e que são utilizados para justificar determinadas estratégias de políticas educativas. Este artigo busca explicitar estes conceitos, considerando que os diferentes usos ou suas diferentes interpretações podem ser conseqüência dos processos histórico-sociais que atravessaram os países nas últimas décadas. O estudo afirma que o conceito de 'qualidade' converte-se num dilema para a definição das políticas educacionais, já que pode ser utilizado com sentidos e conteúdos muito diferentes, e, em alguns casos, antagônicos. Reconhece também a existência de um conteúdo ideológico do conceito quando vinculado à educação.

Palavras-chave educação de qualidade; qualidade da educação; estratégias políticas educacionais; educação e ideologia.

\begin{abstract}
Education of quality' and 'quality of education' are terms repeated in documents and speeches that go with propositions of action in educational field and that are used to justify specific strategies of educational policies. This article intends to explain these concepts, considering that the different uses or different interpretations might be consequences of historical-social processes that pervaded countries in the last decades. The study sustains that the concept of 'quality' becomes a dilemma for the definition of educational policies, because it can be used with very different senses and contents and, in some cases, antagonical, and recognizes the existence of an ideological content of the concept when linked to education.
\end{abstract}

Keywords quality education; education and ideology; educational estrategies policies. 
Dilema (do latim dilemma): Argumento formado por duas proposições contrárias disjuntivamente, com tal artifício que, negada ou concedida qualquer uma delas, fica demonstrado o que se tenta provar.

(Dicionário da Real Academia Espanhola)

\section{Apresentação}

Este trabalho 2 tem como objetivo contribuir com algumas reflexões ao debate que se faz necessário na comunidade educativa, ligado a um conceito que é utilizado no discurso político para justificar determinadas estratégias de políticas educativas.

'Educação de qualidade' e 'qualidade da educação' são dois referentes repetidos nos documentos e discursos que acompanham as propostas de ação no terreno educativo, mas que muitas vezes, como na imagem da bíblica da Torre de Babel, não podemos entender a que aspectos das ações envolvidas fazem referência.

Os diferentes usos ou suas diferentes interpretações podem ser conseqüência dos processos histórico-sociais que atravessaram os países nas últimas décadas. De forma esquemática é possível dizer que a crise dos modelos de Estado Social foi usada pelas tendências neoconservadoras para questionarem muitos dos seus princípios e valores, fundamentalmente aqueles que se expressavam nas políticas sociais destinadas a diminuir as desigualdades. As políticas neoliberais chegaram a revitalizar princípios e pressupostos próprios do 'liberalismo conservador' nas áreas da economia, da política e do pensamento social, no intuito de restaurar e legitimar novas estruturas hierárquicas nas sociedades.

No final do século XX e nos primeiros anos do século XXI se produz uma mudança na orientação ideológica de alguns dos governos latinoamericanos, que impulsionaram, com características e dinâmicas diferentes, estratégias destinadas a superar os problemas econômicos, políticos e sociais, gerados pela aplicação das políticas neoliberais.

Destes três momentos, o presente, caracterizado como 'pós-neoliberal'3, constitui uma etapa histórica de síntese e, como conseqüência, se superpõem concepções, práticas sociais e transformações estruturais, que provêm de todas essas experiências. Os processos sociais de cada país adquirem características diferentes e distintos níveis e graus de complexidade, que são o reflexo das políticas executadas na década de 1990.

Os novos programas políticos propõem, em geral, a recuperação de formas solidárias de redistribuição, maior participação do Estado na regulação 
da economia e das políticas sociais destinadas a recompor os laços de solidariedade como resposta à fragmentação social herdada. O discurso político que expõe estas propostas emprega conceitos que possuem, em muitos casos, uma determinada carga semântica dada pela origem ou pelo uso mais generalizado e, assim, a sua utilização pode prestar-se a confusões.

Michel Apple resume esta idéia quando diz que os conceitos não duram em demasia. Têm asas, para dizer de alguma maneira, e podem voar de um lugar para outro. Este é o contexto que define o seu significado.

Esta é a situação que se apresenta quando se faz referência à 'qualidade da educação', já que existe unanimidade entre aqueles que analisam as diferentes dimensões do fato educativo de reconhecer a dificuldade para encontrar um acordo sobre o seu conteúdo.

Sverdlick (2001) aponta que Rocio Llerena, em seu artigo A investigação educativa para a qualidade, comenta que, em uma revisão da literatura ligada ao tema, encontram-se 950 referências nacionais e internacionais sobre a qualidade da educação, dando a entender que é um conceito que pode ser utilizado com múltiplos sentidos, inclusive em alguns casos antagônicos, ou de forma imprecisa, ambígua, com o objetivo de obter adesões quando isso pode ajudar a alcançar um determinado consenso.

Neste sentido, é necessário ter presente que o conceito de 'qualidade' encontra-se instalado no 'senso comum', por estar relacionado com diferentes experiências pessoais. Sua denominação invoca certas qualidades de um objeto, situação ou experiência, que tenha sido avaliada por cada um de nós, como conseqüência de uma circunstância vivenciada.

A 'boa ou má qualidade' de alguma coisa remete geralmente a situações agradáveis - no primeiro caso - ou desagradáveis - no segundo - e, portanto, a reação frente a essa palavra se encontra condicionada por um sentimento que tem origem num juízo de valor.

O discurso político, que tem como objetivo influenciar o coletivo social para instaurar, manter ou transformar uma determinada ordem social, na exposição dos objetivos do programa faz uso de referentes associados às experiências positivas daqueles a quem está dirigida a proposta, em função da necessidade de somar adesões ou neutralizar resistências.

Essa estratégia muitas vezes oculta as verdadeiras intenções, e nesse sentido pode ser caracterizada como um discurso ideológico. É por essa razão que, na análise das políticas sociais, coincidimos com a opinião de que uma política educativa não é uma sucessão de atuações ou de decisões desconexas, mas que se deve pressupor que umas e outras (ações) são adotadas com a coerência de um programa político, pois o programa político refere-se a valores e opções ideológicas concretas (Pedró e Puig, 1998).

Estas afirmações nos ajudam a formular a hipótese de que a dificuldade para encontrar um sentido único que contenha as múltiplas interpretações 
do conceito de 'qualidade' - quando se refere aos processos envolvidos na educação - deve-se a que esse conceito tem uma origem e um referente específico, associado a um modelo social, e que, como conseqüência, cria confusões ou se ressente de precisão, ou de muitos esclarecimentos, quando é utilizado para definir aspectos do processo educativo que não se ajustam aos parâmetros do sentido originário.

Em outras palavras, a idéia de uma 'educação de qualidade' encontrase originariamente ligada a uma forma de conceber as características e funções que a educação deve possuir e cumprir como ferramenta de formação, para se adaptar às demandas requeridas para reproduzir e potencializar um modelo de desenvolvimento capitalista.

Quando o projeto político se afasta dos valores e princípios desse modelo de organização social, o conceito deixa de expressar o sentido originário e se transforma num referente sem conteúdo específico e passível de interpretações, confusões e manipulações. Uma proposta de educação que não se limite a gerar processos de adaptação passiva à estrutura social, mas que proponha formar para interagir 'em e com' o mundo e 'para' participar dos projetos sociais inclusivos e solidários, não pode ser avaliada com os mesmos critérios utilitaristas que servem para qualificar a qualidade nas sociedades cujas relações sociais empregam a lógica da competência e a sobrevivência do mais apto.

Neste caso e a partir dessa perspectiva é preciso debater a possibilidade de promover um conteúdo de educação que possa ser considerado como portador de um 'sentido e conteúdo' diferente, orientado a dar resposta às necessidades mais urgentes e prioritárias de nossas sociedades.

\section{Qualidade como insumo da economia}

De acordo com o Dicionário da Real Academia Espanhola, 'qualidade' significa 'propriedade ou conjunto de propriedades inerentes a alguma coisa, que permite julgar seu valor'. Esta definição põe em evidência a necessária relação que deve existir entre as propriedades de 'algo' e os valores que estão associados a elas. Essa relação implica, em consequiência, considerar ambos os termos vinculados.

$\mathrm{Na}$ busca por alcançar maior precisão ou uma determinada interpretação do conceito, as opiniões se abrem num amplo leque de sentidos. Algumas delas nos ajudam a entender a busca.

Uma especialista em educação assinala a necessidade de precisar o sentido e conteúdo atribuído às práticas envolvidas no processo educativo, para poder compreender seus verdadeiros fins. Em suas palavras, 
é possível afirmar que a qualidade supõe uma valoração sobre as 'qualidades' daquilo ao que se aplica o conceito... De modo que se vamos falar sobre a qualidade da educação, temos que levar em conta que estamos implícita ou explicitamente propondo uma caracterização da educação à qual nos referimos; às concepções que temos em relação com a escola e suas funções; dos processos de ensino-aprendizagem; da ação dos professores, dos processos de avaliação etc. (Sverdlick, 1997, p. 9).

Outro pesquisador destaca a utilização que se fez destes conceitos na década de 1990 e que serviu para justificar ações que associavam no discurso a experiências ou sentimentos positivos dos destinatários. Em suas palavras,

A qualidade é seguramente um dos problemas mais propagados nos anos 90. (...) Desta maneira, nos é oferecido como um grande guarda-chuva protetor, carregado de promessas. A paixão pela qualidade, como também o direito cidadão à qualidade, parece a conquista definitiva de um novo estágio de desenvolvimento e progresso, ao que ninguém, por sua benevolência, pode negar-se, ao que todos (não se deve esquecer que, na realidade, só alguns) temos direito e possibilidade de realização (...) É muito mais simples em sua contextura, gosta mais da lógica dos sentimentos e sensações, de estratégias e procedimentos, mais de pragmática que de semântica, de formas e aparências como substituição ou camuflagem de substâncias e realidades. Cuida com atenção dos slogans e orientações para os cidadãos, sobretudo na sua condição de consumidores (Escudero, 1999, p. 2).

\section{Para concluir que}

(...) a qualidade dos anos 90 projeta seus raios de salvação sobre a educação. Naturalmente, também como definitivos guarda-chuvas de garantia e promessas de melhor educação, uma educação de qualidade (Escudero, 1999, p. 2).

Um terceiro analista acha necessário que as ações de avaliação sobre as conquistas da educação devem surgir de um primeiro acordo, aquele que se refere ao sentido que deve ser atribuído ao conceito de qualidade, já que sua imprecisão pode torná-lo um 'sem sentido', pois cada um pode lhe atribuir aquilo com o que se identificar melhor. Por esse motivo, ele diz que

além dos exercícios de medição de qualidade destinados a avaliar o porcentual de logro dos objetivos pedagógicos, está pendente um acordo sobre o que se entende por qualidade da educação. De fato, cada pessoa, pelo único fato de ter ido à escola, tem sua idéia a respeito. Com maior razão, cada grupo de interesse tem uma 
idéia do que é uma educação de qualidade relativa a suas posturas mais fundamentais (...) (Casassus, 2003, p. 65).

\section{E destaca que}

(...) até um par de décadas atrás, qualidade da educação era uma idéia alheia e até anacrônica para o universo mental dos educadores. (...) em meados dos anos 80, a percepção predominante era que uma pessoa tem uma melhor educação quando tem mais anos de escolaridade (Casassus, 2003, p. 65).

Essas comparações quantitativas logo deram lugar às medições qualitativas e como "resultado (...) tem terminado por fixar-se em seu foco atual, qual é a observação e a medição do logro acadêmico" (Casassus, 2003, p. 65).

Finalmente, uma tentativa de classificação do conceito é proposta por uma pesquisadora, que cumpriu funções ministeriais e é consultora internacional para organismos multilaterais (Banco Mundial, Organização dos Estados Americanos, Unesco). Segundo ela, o conceito de qualidade, quando referido à educação, é:

1 - Complexo e totalizante (...) permite ser aplicado a qualquer um dos elementos, que entram no campo educativo.

2 - Social e historicamente determinado (...). É um conceito socialmente determinado, que tem suas próprias definições e estas definições surgem fundamentalmente das demandas que o sistema social faz à educação.

3 - É constituído em imagem-objetivo da transformação educativa (...) é um conceito útil, já que permite definir a imagem-objetivo do processo de transformação e, portanto, se constitui no eixo que rege a tomada de decisões. A qualidade da educação é, de fato, o orientador de qualquer transformação.

4 - É construído em um padrão de controle da eficiência do serviço. (...) a qualidade da educação pode servir de padrão de comparação para ajustar as decisões e reajustar processos (Aguerrondo, 1993).

E conclui que, "(se) há consistência entre o projeto político geral vigente na sociedade e o projeto educativo que opera, é essa relação a que define a existência da "qualidade"' (Aguerrondo, 1993).

Esta última afirmação põe em destaque a necessária relação que existe entre educação e política e, por esse motivo, pode-se concluir que o conteúdo do conceito 'qualidade' está definido e determinado pela orientação política.

Diante do que já foi dito, é possível observar algumas das formas como este tema foi abordado. Essa circunstância nos habilita a tentar realizar alguns aportes que contribuam com o debate. 
Em primeiro lugar, compartilhamos com as afirmações de que as decisões políticas que impulsionam estratégias, consideradas necessárias para alcançar uma 'educação de qualidade', trazem sentidos 'implícitos' ou 'explícitos' como parte de um programa político concebido e executado para concretizar um projeto social.

Neste sentido, a 'qualidade', considerada como um 'conjunto de propriedades' que são atribuídas ao que se quer designar com esse conceito, encontra-se em relação com uma escala de valores que é própria da filosofia que fundamenta toda proposta política e constitui um dos pontos de partida desde onde vão ser estabelecidos objetivos e/ou prioridades políticas.

Em segundo lugar, a exigência de uma 'educação de qualidade' por parte dos membros de uma sociedade vincula-se de forma direta às experiências e expectativas daqueles que as possuem e consideram que, tendo acesso a esta ferramenta, poderão obter certa vantagem para concretizar determinados fins. Nesse caso, o sentido atribuído ao conceito de 'qualidade' provém das necessidades e desejos, tanto dos sujeitos em forma individual quanto dos diferentes grupos ou setores sociais. Dessa forma, nas últimas décadas generalizou-se nos fóruns nacionais e internacionais o interesse pela 'qualidade' como um atributo necessário da educação para favorecer as possibilidades de desenvolvimento econômico.

Algumas declarações e documentos deram ênfase ao vínculo entre 'qualidade e eqüidade', sendo o primeiro conceito considerado condição necessária para a realização do segundo. Esta associação entre dois referentes que possuem, no imaginário social, uma carga valorativa positiva aparece como uma tentativa de outorgar-lhe maior precisão.

Contudo, o conceito de 'eqüidade' apresenta as mesmas dificuldades para atribuir-lhe um sentido inequívoco, já que sua definição surge de uma oposição: "justiça natural em oposição à lei positiva"; e num princípio distributivo: "dar a cada um o que merece".

Ambas as definições baseiam-se em juízos de valor e, em conseqüência, as diferentes concepções políticas podem atribuir conteúdos diferentes a essas afirmações. O que se entende por 'justiça natural'? É a que os liberais aceitam? É a que os conservadores defendem? Quem, como e com que critério se define o que 'cada ser humano merece'? Estas são algumas das interrogações que surgem com essas afirmações. Portanto, tal relação, em vez de precisar o conceito de qualidade, acrescenta confusão.

Fazendo um pouco de história, a vinculação entre 'educação e qualidade' adquire centralidade na análise e nas estratégias políticas a partir dos resultados de um estudo sobre o desempenho dos estudantes norteamericanos, considerando os resultados atingidos nos diferentes níveis do sistema. Como assinala Casassus, “o interesse pela qualidade da educação surgiu pela primeira vez nos Estados Unidos, em 1983, com a publicação 
do Relatório da Comissão de Excelência em Educação (Nation at Risk)" (Casassus, 2003, p. 63).

Este relatório 4 destacava que, em termos relativos, ampliava-se a lacuna entre a formação que os estudantes norte-americanos recebiam e a dos outros países com os quais competiam, em termos econômicos e tecnológicos. As causas desse desequilíbrio eram atribuídas, entre outras razões, à influência de teorias educativas 'progressistas' que tinham deslocado os conteúdos e métodos tradicionais na educação, gerando a crise.

As conclusões do relatório foram usadas como argumento por parte dos grupos políticos conservadores dos Estados Unidos para reformular e reorientar os conteúdos da educação, como também a dinâmica e as características dos modelos institucionais.

Essas idéias foram logo difundidas em muitos países latino-americanos como filosofia implícita dos programas neoliberais que eram financiados pelos organismos multilaterais (Torres, 1986).

Esse renascer das propostas conservadoras revitalizou uma perspectiva de análise sociológica, que liga a economia à educação, com a finalidade de medir sua incidência sobre o processo produtivo.

O 'funcionalismo' constitui, nas sociedades capitalistas, uma das teorias que atingem maior influência na área dos estudos sociais, logrando uma forte incidência nos níveis de elaboração das políticas educacionais, prioritariamente nas áreas sócio-política, didática e de gestão.

Nesta teoria, duas orientações se destacam: o "funcionalismo tecnoeconômico", encarregado de analisar a relação entre educação e desenvolvimento econômico, por mediação da tecnologia; e o "funcionalismo meritocrático", que se centra na questão da 'igualdade de oportunidades' de educação, e da incidência que produz, com a melhoria das rendas individuais, o acesso aos diferentes níveis do sistema educativo (Gil Villa, 1994, p. 50).

Como resultado destes estudos, atinge um alto nível de desenvolvimento e expansão a denominada 'Teoria do Capital Humano', que se sustenta sobre o princípio de que a educação constitui um investimento que as pessoas fazem em si mesmas, para melhorar, no futuro, sua renda e suas condições de vida.

Este princípio é utilizado em dois níveis da análise econômica: um macro e outro micro. O primeiro estuda a incidência do incremento dos custos públicos e privados em educação sobre a renda nacional. O segundo analisa como a maior acumulação de anos de educação em nível individual dará lugar a um incremento da produtividade futura do trabalhador e, portanto, um aumento da sua renda (Gil Villa, 1994, p. 53).

Tais abordagens foram utilizadas por parte dos pesquisadores dos governos e dos organismos internacionais com a finalidade de avaliar a relação 
'custo-beneficio', tanto em nível individual como em relação aos índices que expressam o crescimento econômico.

Esta análise contém uma escala de valores que serve para estabelecer prioridades na tomada de decisões de políticas educacionais e são, além disso, as que outorgam o sentido originário do conceito 'qualidade'.

O desenvolvimento dos estudos que ligaram a economia à educação tornou-se uma espécie de 'paradigma' empregado pelos planejadores e executores de políticas educativas na elaboração de propostas. É a partir daí que começa a considerar-se que a educação prepara os 'recursos humanos' que vão ser demandados pelos processos produtivos. Ou seja, que para o funcionalismo, a educação cumpre uma série de funções na sociedade, tanto em relação ao subsistema cultural quanto ao político ou ao econômico, como são as funções de socialização, de legitimação ou de seleção e classificação da mão-de-obra (Guerrero Serón, 2003).

De acordo com esta perspectiva, a 'educação de qualidade' consiste na formação certificada que oferece as ferramentas mais eficientes para adquirir os conhecimentos, as atitudes e os valores exigidos pelo sistema econômico, pelo regime político e pela convivência social numa determinada sociedade. A educação de 'alta qualidade' é a que provê as capacidades 'funcionais' para se chegar ao maior e melhor nível de integração à sociedade, enquanto a 'baixa qualidade' é característica da educação que não os contempla. As graduações entre um extremo e outro são flexíveis e relativas.

A filosofia individualista é aquela que atribui sentido a esta lógica de raciocínio, na medida em que parte do pressuposto de que nas sociedades capitalistas é necessária uma 'competência de talentos' e que é aí onde se produz a seleção natural que premia os que triunfam.

Na segunda metade do século XX, algumas das conclusões do relatório Nation at Risk foram utilizadas pelo conservadorismo político e social, para questionar os princípios e valores das 'teorias críticas' da educação, revalorizando os modelos educativos tradicionais que aportam conteúdos pragmáticos e promovem a restauração dos sistemas hierárquicos nas relações pedagógicas e na organização das instituições.

A propagação dessas idéias ao restante dos países acompanhou a estratégia do governo dos Estados Unidos, que reclamavam a adequação dos 'estilos de desenvolvimento' dos países sob sua influência ou domínio, para torná-los compatíveis com os seus interesses e necessidades de potência hegemônica num mundo unipolar. O Tratado de Livre Comércio das Américas é um exemplo.

Estes objetivos foram possíveis de se concretizar, embora de forma parcial, em virtude do controle que esse país exerce sobre alguns dos principais organismos multilaterais, assim como da cooptação de intelectuais e políticos e do financiamento de reformas econômicas e/ou políticas em 
alguns países, prioritariamente para os governos que aceitam incorporar-se a essa nova divisão internacional do trabalho.

Nas últimas décadas, a teoria do 'capital humano', como expressão da relação educação-economia, adquire novas características que se adaptam às necessidades exigidas pela globalização econômica, apesar de manter seus valores e princípios.

A esta lógica de raciocínio, baseado no cálculo 'custo-benefício' e 'inversão-produtividade', que dá o sentido originário da teoria, acrescenta-se outra que avalia os resultados a partir da equação 'insumo-produto'.

Através desta relação, procura-se, no âmbito da educação, conquistar mudanças na cultura institucional, nos valores que guiam as práticas docentes, nas formas como os pais devem observar e avaliar as instituições etc. Todas estas questões assumem como princípio a busca da eficiência do investimento, que se consegue quando se produz um maior controle sobre a produtividade. $\mathrm{O}$ termo accountability (que não tem tradução direta nem para o espanhol nem para o português) é o conceito que expressa esta tendência e o mesmo "faz referência (...) primeiramente aos resultados em termos de aprendizagem e a utilização que os atores têm feito dos recursos para alcançar esse objetivo" (Corvalán e McMeekin, 2006, p. 12).

De acordo com este raciocínio e a partir de duas expressões utilizadas para a tradução -

'rendição de contas' e 'responsabilização' -, podemos ter uma aproximação à temática em questão, entendendo que a accountability alude a ambos os sentidos: em parte é uma prestação de contas aos interessados ou envolvidos pelos resultados do processo educativo, o que por sua vez, se espera, tenha como conseqüência um incremento dos níveis de responsabilização de cada ator sobre tal processo. (...) A prestação de contas de contas na accountability educacional refere-se, então, primeiramente aos resultados em termos de aprendizagem e à utilização dos recursos pelos atores do processo para conseguir esse objetivo (Corvalán e McMeekin, 2006, p. 11-12)5.

Estas idéias, que foram introduzidas pela economia na educação, incorporam um novo raciocínio à avaliação dos resultados dos processos educativos e servem de argumento aos programas políticos que adotam a 'eficiência' como princípio que rege as políticas públicas.

Tendo como base estas premissas, os 'bons' resultados da educação podem ser reconhecidos, por um lado, a partir de uma equação que avalia os resultados em relação ao investimento realizado, na busca por conseguir maior competitividade da economia e, por outro, quando os agentes envolvidos (dirigentes e docentes) se responsabilizam pelas conquistas ou fracassos dos alunos na aquisição das capacidades requeridas pelo modelo social. 
O princípio da competência encontra-se implícito nesta proposta e, por isso, as decisões políticas - quando estão regidas por esta lógica econômica assumem uma escala de valores baseada no cálculo que mede a relação 'custo-benefício', deslocando as perspectivas que possuem como referente valores que qualificam as práticas sociais a partir de uma ótica solidária e não mercantilizada.

Na década de 1990, na maioria dos países latino-americanos, executaram-se políticas econômicas e sociais com um conteúdo neoliberal. Em alguns deles, como Chile e Argentina, foram o fundamento das reformas educativas. Nestes casos, a 'sociedade', como âmbito de expressão da vontade e do interesse privado, deveria substituir o Estado em funções e responsabilidades que historicamente haviam sido atribuídas e destinadas a este último.

No contexto destas reformas, a 'qualidade da educação' foi considerada como o resultado da competência de projetos interinstitucionais, destinados a satisfazer as múltiplas demandas que cada indivíduo reclama, de acordo com suas expectativas, necessidades e possibilidades. Do acerto ou não dessa 'livre escolha' dependerão suas possibilidades de sucesso em termos econômicos e sociais. A responsabilidade é individual.

\section{Qualidade, entre o'público' e o 'privado'}

Na análise da questão da qualidade em educação, é também necessário considerar que, na maioria dos sistemas educativos nacionais, convivem dois âmbitos de domínio institucional: um público e estatal; o outro, privado. As características e dimensões de cada um desses âmbitos refletem as particularidades de seus processos históricos.

Nos momentos fundacionais dos estados nacionais, as condições políticas exigiam controle estatal sobre a educação. Segundo uma especialista,

os mesmos fundamentos teóricos do Estado Liberal, ao romper com a sociedade estamental e proclamar a igualdade dos cidadãos, deram base à concepção de um sistema escolar ao qual todos os cidadãos tinham direito a aceder e cuja possibilidade estaria garantida pelo Estado, através da organização de um sistema escolar público e universal (Ossenbach Sauter, 2002, p. 35).

Esta necessidade política implicava, em alguns países, uma contradição com alguns princípios do liberalismo, fundamentalmente aqueles que negam ao Estado autoridade para intervir sobre as decisões que se consideram próprias dos indivíduos, no seu âmbito privado. No entanto, frente ao monopólio histórico da Igreja sobre a educação, a 'razão de Estado' 
antepôs o interesse geral ao que podia ser considerado como o interesse de um setor da sociedade.

Posteriormente a essas primeiras etapas, a definição sobre o que é de responsabilidade ou de interesse público ou privado foi sempre motivo de controvérsias, já que as questões envolvidas, assim como a definição dos seus limites, constituem um elemento central da luta política6.

Por razões relacionadas com o controle social, e levando em conta as funções que a educação cumpre em nossas sociedades, o poder político precisa, para poder cumprir com seus objetivos, ter algum grau de interferência em ambos os circuitos. No entanto, a sua maior responsabilidade é a que se verifica através do sistema público estatal, quando é predominante.

Em outro sentido, as formas e características da vinculação entre o poder público e os interesses dos grupos ou setores sociais envolvidos com a educação privada estará determinada pelo grau de afinidade entre os princípios e valores que sustentam ambos os setores.

No âmbito privado, os ideais de formação e as características institucionais podem adquirir, geralmente, maior nível de autonomia por serem instituições particulares que respondem a interesses específicos. Educar num sistema de valores religiosos ou para inserir-se com eficiência no mercado de trabalho ou, simplesmente, como investimento que oferece bons lucros constituem (isoladamente ou de maneira convergente) os objetivos dos modelos de instituições particulares, que existem na maioria dos nossos países.

Os diferentes níveis do sistema educativo podem ser motivo de particular interesse para aqueles que se propõem, em forma prioritária, alcançar alguns dos objetivos mencionados e que avaliam que essa é a forma de consegui-lo.

A seleção e integração do corpo docente, os sistemas de ingresso dos estudantes, o valor das mensalidades; a organização e os conteúdos do currículo, o regime disciplinar, o regime institucional etc. evidenciam a filosofia que o projeto educativo possui, ainda que nem sempre os reais interesses se manifestem de forma explícita.

A 'qualidade' é um dos termos mais utilizados pelo privado para apresentar um modelo de educação à sociedade e essa denominação encontra-se associada tanto ao 'senso comum' (ao que fizemos referência anteriormente) como aos interesses sociais ou ideológicos dos que podem estar interessados em optar por essas instituições.

As razões expostas nos permitem afirmar que, entre os objetivos destes projetos educativos, é possível identificar aqueles orientados a formar os 'intelectuais tradicionais', assim como os destinados a gerar os 'intelectuais orgânicos', requeridos para a estabilidade e o desenvolvimento do sistema social. 
Nessas instituições, o apelo à 'qualidade' apresenta menos ambigüidade, já que a população que a exige é mais homogênea em termos sociais ou ideológicos e, por isso, coincide tal projeto com as expectativas dos que o procuram. Em alguns casos, a qualidade pode estar associada a princípios e valores religiosos ('bom devoto'), a capacidades instrumentais ('eficiente trabalhador'), a uma expectativa de inserção social (empresário/ proprietário/pessoa destacada, profissionais) ou a uma livre combinação dos mesmos.

O que aqui está expresso não significa desconhecer a existência de instituições privadas, de orientação progressista, criadas a partir de posições alternativas ao sistema oficial. Cooperativas, associações comunitárias, sindicatos, entre outros, também oferecem propostas diferentes das oficiais, ainda que a sua expansão seja menor, quando comparada a outros tipos de instituições e, em geral, atendem a uma população mais heterogênea, em termos sociais.

Em relação à 'educação pública', sua origem - como já foi mencionado - respondeu a uma necessidade política e transformou-se em uma conquista histórica do bem comum - (já que) contribui para criar esse bem (Gimeno Sacristán, 2001).

Uma das diferenças quanto à educação privada é que "o sistema público é governado por representantes do todo público e não por pessoas particulares (como ocorre no privado). O público é o que diz respeito à competência do governo ou dos governos quando há diferentes níveis na administração centralizada" (Gimeno Sacristán, 2001, p. 18).

Gimeno Sacristán introduz outro elemento para o debate, ao afirmar que

ensino público é mantido pelo Estado, mas não deve ser um monopólio estatal, ainda quando o Estado tenha um papel muito importante por desempenhar ao representar os interesses da sociedade no seu conjunto. A instância do público se opõe tanto ao que é privado (não possível de ser desfrutado por todos) como à apropriação que uma parte da sociedade pode fazer dele, subtraindo-o da totalidade da sociedade (Gimeno Sacristán, 2001, p. 25).

Esta definição para o que é público como um espaço não limitado às ações geradas a partir do Estado, no sentido estrito (público = não estatal) possui duas variáveis de interpretação: a primeira, que responde a uma visão ampliada do 'Estado' - como "sociedade política mais sociedade civil" (Portelli, 1997); e a segunda, que inverte o sentido dado na primeira, associando o 'público' a todas as relações que não pertencem ao âmbito privado, ou seja, à maioria das relações que se estabelecem na sociedade e que estão orientadas e definidas por um 'natural e espontâneo interesse 
coletivo' que se articula e se regula pelo mesmo princípio que rege o intercâmbio de bens no mercado.

A primeira interpretação serve para promover ações que favoreçam a generalização e ampliação das práticas democráticas, enquanto que a segunda, ao reduzir a diferença entre os âmbitos público e privado, propõe ampliar a privatização ${ }^{7}$ do espaço social8.

A definição da 'qualidade da educação' para o âmbito público, e considerando estas duas interpretações, põe em evidência a confusão que é gerada.

Nessa disputa por lhe outorgar um conteúdo claro ao conceito, Gimeno Sacristán reclama que, com relação à educação pública,

qualidade tem que ser uma característica essencial, não permitindo que o debate em torno desta exigência seja monopolizado pelo conservadorismo político, pelos enfoques empresariais da gestão ou pelos tecnocratas assépticos, dando a sua peculiar versão sobre o que devemos entender por qualidade (Gimeno Sacristán, 2001, p. 32).

Para este autor, as definições sobre o que se entende por qualidade da educação permitiriam elaborar estratégias adequadas para dar respostas às necessidades das maiorias sociais, já que é responsabilidade do Estado o atendimento das necessidades do coletivo social.

Nos últimos anos, as referências a este tema tomaram uma nova dimensão, constituindo-se em tema central dos debates nos fóruns internacionais sobre educação.

\section{Qualidade como preocupação nos fóruns internacionais}

A Conferência de Jomtien (Tailândia), em 1990, foi um dos principais espaços de reunião entre governos, agências internacionais e diferentes organizações não-governamentais relacionadas com a educação, para definir linhas de ação e estabelecer compromissos para responder às urgentes necessidades educativas de todos os países, mas, de forma prioritária, às dos países de menor desenvolvimento econômico.

A qualidade transformou-se no tema central da segunda reunião, realizada em Nova Déli, do Fórum Consultor Internacional sobre Educação para Todos, que tinha sido criado na Conferência de Jomtien para fazer um acompanhamento, nos diferentes países, dos programas postos em execução a partir deste encontro.

Simultaneamente, e também no início da década de 1990, começam a acontecer reuniões de cúpula ibero-americanas de chefes-de-estado e de 
governo, as quais tratam de temas cuja importância podem demandar esforços comuns. Destas reuniões participam governantes dos países latinoamericanos, Espanha e Portugal.

Nas primeiras reuniões, realizadas no México e em Madri, discutiram-se as metas que se pretendiam alcançar no decênio, tomando como ponto de partida uma crítica às "mazelas que a região carrega" (citação textual do documento). Como um dos temas importantes, houve consenso em que a educação constará como um item específico dentro de um contexto, onde os chefes de governo destacam também a inegável necessidade de incentivar o desenvolvimento econômico e social e que todos os representantes se comprometem a um profundo reajuste nas economias para alcançar a recuperação e o crescimento com eficiência (Martinez Usarralde, 2005).

Na reunião de cúpula realizada em 1995 em São Carlos de Bariloche (na Argentina), foi assinado um acordo onde os governos devem ter como objetivos a democratização do ensino, a geração de condições de qualidade na educação e a atenção exigida pelo princípio da eqüidade, concedendo ao Estado, para tal fim, um papel estratégico (Martinez Usarralde, 2005).

Como resultado destas reuniões organizam-se as conferências iberoamericanas de educação, promovidas pela Organização de Estados Iberoamericanos para a Educação, a Ciência e a Cultura (OEI), das quais participam ministros da área ou chefes de delegação. Nesses âmbitos, o tema da qualidade volta a ser incorporado e o objetivo central é concretizar os acordos alcançados nas conferências dos chefes-de-estado.

Cada uma das reuniões estabelecia um tema central para ser debatido. No que se refere à 'qualidade da educação', a questão é examinada pela primeira vez na V Conferência de Buenos Aires, em 1995. Nesta oportunidade, o eixo definido é a busca de um compromisso com a qualidade e a eqüidade, modernização das administrações, formação em valores e eqüidade para um mundo em transformação.

Como se pode observar, a qualidade, nesta oportunidade, está associada a mudanças ao nível das instituições educativas, assim como aos valores exigidos por estas transformações. No caso da Argentina, estas orientações apresentam-se no momento da instrumentação da Lei Federal de Educação, que introduz modificações no Sistema Educativo, com uma clara orientação neoliberal. Um exemplo disso é a caracterização da 'educação pública' como âmbito único, tendo como conseqüência que a diferenciação entre 'público e privado' fica reduzida a uma questão de 'gestão'.

Tal questão volta a ser priorizada na Conferência de Havana, em 1999, através do eixo 'Qualidade da Educação: qualidade, desenvolvimento e integração frente ao desafio da globalização'. Nesse caso, a qualidade está relacionada a uma perspectiva macro - 'a globalização' - associada ao 
desenvolvimento e integração. A diferença de dimensão, com relação ao proposto na conferência de Buenos Aires, é evidente.

Todas estas referências evidenciam, como e em que momento começa a se instalar na agenda pública esta temática e isso confirma que os problemas entram no discurso e, portanto, na existência, como reforço das ideologias, não simplesmente porque estão aí ou porque são importantes para o bemestar (Edelman, 1991).

Esta definição ajuda a compreender que a 'qualidade da educação' é uma preocupação política, surgida num momento da história de nossas sociedades e prioritariamente associada a avaliações de resultados, no campo do desenvolvimento econômico.

Se bem podemos observar que a questão foi tratada em duas reuniões, na de Buenos Aires os debates eram orientados para definir novos modelos institucionais e de gestão. Para a primeira reunião, foram apresentados à sociedade os modelos de escolas charter e propostas de financiamento através dos 'bônus educativos' ou de diferentes formas de 'autogestão'. Já no caso da Conferência de Havana, em Cuba, a 'globalização' foi definida como um desafio, um desafio político para os países, e é de se supor - estamos nos referindo a uma reunião que aconteceu em Cuba - que o enfrentariam com um projeto político considerado conveniente.

Na Argentina e na maioria dos países da América Latina, as propostas mencionadas foram impulsionadas e financiadas pelo Banco Mundial, instituição comprometida com a estratégia dos Estados Unidos para estabilizar um sistema unipolar. Entre os desafios com que, segundo esta instituição, se deparavam os 'países em desenvolvimento', destacava-se a qualidade vista como um problema generalizado que afeta a todo o mundo em desenvolvimento (Coraggio e Torres, 1997).

No entanto, para a pesquisadora Rosa María Torres, a qualidade educativa, na concepção do Banco Mundial, seria o resultado da presença de determinados gastos que intervêm na escolaridade (Coraggio e Torres, 1997). O elemento comum das propostas do Banco Mundial é o traço economicista de seus programas que promoviam, entre outras políticas: limitação da responsabilidade do Estado na sustentação do sistema educativo, estabelecendo como prioridade o nível básico de formação; introdução dos mecanismos de mercado nas relações entre os gastos que intervêm no processo educativo, envolvendo a família no seu financiamento; a promoção dos valores próprios do ideário neoliberal como modelo social etc.

Todas as propostas de mudança foram apresentadas como estratégias inevitáveis para modernizar a sociedade e integrar-se à nova ordem mundial. O 'desenvolvimento econômico' era considerado como a conseqüência natural da aplicação de políticas destinadas a produzir mudanças ao nível 
da economia, legislação social, relações do Estado com a sociedade etc., mas, fundamentalmente, uma mudança nos princípios e valores sociais.

Estes modelos não contemplavam particularidades. Um exemplo disso nos é oferecido por Rosa María Torres, quando conta a sua experiência como assessora educativa da Unicef, por ocasião de uma viagem a um 'país caribenho'. O relato começa com estas palavras:

O ministro da educação deste país caribenho aproxima-se de sua escrivaninha e, com grande satisfação, me entrega três volumes. Diagnósticos, Recomendações e Plano, respectivamente, para a educação do seu país nos próximos cinco anos. (...) Folheando somente o primeiro volume, confirmo o que temia: trata-se do diagnóstico estandardizado em torno da educação e sua problemática, o que se repete com assombrosa uniformidade (...) nos países do chamado Terceiro Mundo e nos da América Latina e do Caribe em particular (Torres, 2005, p. 37).

Quem faz o prólogo do livro do qual extraímos esta citação destaca que uma das qualidades desta pesquisadora é a sua capacidade de observação minuciosa que se reflete na descrição das características do país que visitava e que permitem reconhecê-lo como um dos mais pobres e atrasados da América Latina. Ao finalizar o capítulo, a pesquisadora conclui que

O ministro deste pequeno país caribenho pediu-me opinião e eu, com toda a franqueza, a dou. Por mais que eu tenha procurado, tratando de ler nas entrelinhas, entre os quadros apresentados, não encontrei seu país nos relatórios. (...) O Diagnóstico, as Recomendações e o Plano poderiam referir-se a praticamente qualquer país do planeta. Por trás da linguagem fria e das cifras impessoais não há história, não se percebe uma pitada de cultura, algo que permita, enfim, entender de que classe de país é esse, por que e como chegou onde está, como é a sua gente, sua juventude, seus professores... o que pensa o seu povo sobre a educação que tem e que classe de educação gostaria de ter (Torres, 2005, p. 40).

Este relato torna claro como muitos dos programas e propostas elaboradas a partir de diferentes organismos internacionais não têm o objetivo de atender as necessidades específicas das sociedades onde se aplicam, mas tão-somente correspondem ao interesse de gerar processos compatíveis com o dos países que fixam as políticas desses organismos.

O expressado até aqui permite reconhecer a existência de um conteúdo ideológico do conceito de 'qualidade', quando vinculado com educação.

O próprio conceito de 'qualidade' converte-se num dilema para a definição das políticas educacionais, já que pode ser utilizado com sentidos e conteúdos tão diferentes que, em alguns casos, podem até chegar a ser antagônicos. 
Na sua origem e nas orientações dos programas de instituições internacionais, como o Banco Mundial, e dos governos da maioria dos países capitalistas desenvolvidos (que são também quem definem as políticas desses organismos), a 'qualidade da educação' é medida pelo grau de integração e adaptação às condições exigidas por esse modelo social, adaptada às condições históricas existentes.

Este é o sentido originário do termo e a forma mais generalizada de utilização, o que o transforma numa expressão ligada ao pensamento hegemônico nas sociedades capitalistas.

É por isso que a proposta de uma 'educação de qualidade' converte-se num elemento vinculado de forma direta às práticas e às condições de existência de certos grupos ou classes sociais, no entanto converte-se num referente ambíguo, impreciso e confuso quando aparece vinculado com a educação que é oferecida às maiorias sociais.

De acordo com o exposto, surge uma interrogação que nos põe diante de uma disjuntiva: é possível empregar o conceito 'qualidade da educação' para definir os objetivos de um projeto ou programa educacional que se proponha concretizar uma alternativa libertadora frente à alienação da qual a sociedade capitalista é portadora? Uma educação que contribua para a formação de um sujeito social, que permita orientar seus pensamentos e ações para construir uma sociedade distinta em valores e objetivos, com relação aos da sociedade capitalista, pode ser qualificada como uma 'educação de qualidade'?

\section{Educação com sentido e conteúdo}

Boaventura dos Santos sustenta que

os instrumentos hegemônicos que temos são as semânticas legítimas da convivência política e social. (...) [Isto] é um problema complicado porque se são instrumentos hegemônicos, por definição não vão resolver nossas inquietações, nossas aspirações e não vão conseguir o que desejamos, que é uma sociedade mais justa, reinventar a emancipação social (Souza Santos, 2006, p. 72).

A partir deste ponto de vista, a confusão gerada pelo conceito de qualidade da educação está instalada na sociedade. Pelo exposto até aqui, vemos que se pode fazer referência a esta idéia partindo de posições políticas e ideológicas distantes entre si. O Banco Mundial promove mudanças nos sistemas educativos com o suposto fim de melhorar a qualidade; a Unesco organiza fóruns e programas de acompanhamento dos acordos intergovernamentais sobre a qualidade da educação. Nas últimas reuniões de cúpula 
de governantes e nas conferências ibero-americanas de educação, governos de países com condições e projetos político-sociais muito diferentes referiram-se à importância de uma educação de qualidade.

No entanto, não é possível afirmar que essas referências tenham muitos pontos em comum ou que exista total coincidência sobre o conteúdo dado a este conceito; ao contrário, as diferenças existentes nos projetos políticos e modelos sociais dos países envolvidos permitem deduzir que cada um deles interpreta, desde a sua própria ótica e em função de seus próprios interesses e necessidades, a idéia de uma educação de qualidade.

Sendo assim, pode-se entender a idéia de qualidade da educação como um conceito que expresse um interesse comum de todas as sociedades? Ou será que a pergunta deveria ser: qual é o interesse político pela generalização desse conceito? A quem favorece a confusão que se gera a partir desta formulação?

Talvez tenha chegado o momento de começarmos a pensar em utilizar outros conceitos para nos referirmos àquelas propostas de política educacional que tenham como objetivo promover uma educação que considere o ser humano como uma totalidade que deve interagir com a sociedade de forma consciente, e não como quem é chamado a concretizar um legado natural.

Em busca de um discurso alternativo, podemos pensar na idéia de uma educação que seja portadora de 'sentido' e 'conteúdo'.

Esta qualificação da educação supõe a necessidade de desenvolver, nos seres humanos, as duas dimensões requeridas para assumir uma atitude participante e crítica na sociedade.

Uma educação com 'sentido' pode ser definida como aquela que contribui para o desenvolvimento de capacidades que permitem ao sujeito compreender os processos sociais como materialização das ações humanas, assim como o conhecimento das formas como são geradas as riquezas e os diferentes mecanismos que podem ser adotados para a sua distribuição.

Além disso, tal proposta de educação supõe o desenvolvimento de capacidades que permitam diferenciar as virtudes, defeitos e potencialidades da democracia, para favorecer uma convivência inclusiva fundada em valores que recuperem uma perspectiva integral, uma 'ecologia de saberes' 9 ; a compreensão da importância de generalizar os conhecimentos científicos para conseguir melhorar as condições de vida na sociedade e o reconhecimento da cultura como resultado das práticas sociais através da sua própria história.

Uma educação com 'conteúdo' define-se como aquela que pode brindar uma formação adequada para atuar sobre a própria realidade social, mas não como um sujeito sobredeterminado por alguma razão genética, cultural ou metafísica, e sim um sujeito histórico que pode formar-se para o trabalho, e 
não somente para o emprego, que pode conhecer e desenvolver a ciência para utilizá-la em benefício da sociedade; em outras palavras, os conhecimentos que permitem atuar sobre a realidade social, na perspectiva de implicar-se com a construção de uma sociedade mais justa.

Estes conceitos, associados à educação, pretendem assinalar uma diferença entre uma idéia que se baseia na relação entre 'custo-benefício', 'insumo-produto', 'utilidade-inutilidade', 'lucros-perdas' e a outra, que toma como ponto de partida o reconhecimento do ser humano de forma integral a partir do desenvolvimento de todas as capacidades e não somente daquelas que são necessárias para a reprodução e permanência (continuidade) de uma determinada ordem social capitalista.

Uma educação com 'sentido e conteúdo' pode constituir-se numa alternativa à idéia de uma 'educação de qualidade', enquanto esta última possui um maior vínculo com as teorias educacionais que relacionam, de maneira prioritária, a educação com a economia, como uma das funções necessárias para abastecer de elementos requeridos ou demandados pela economia capitalista.

Não é possível fazer referência a uma 'educação de qualidade' se o modelo de homem que se pretende formar não possui as 'virtudes' que lhe demanda um modelo social baseado na competição e na luta pela apropriação ilimitada de bens materiais. Dessa forma, a idéia de uma 'educação de qualidade' não pode ser separada da concepção e do modelo de 'desenvolvimento', numa sociedade capitalista.

É possível interpretar que quando um governo propõe uma 'educação de qualidade' está fazendo referência a conteúdos destinados a formar sob valores que dêem prioridade ao 'ser' sobre o 'ter'? Que concebem as formas de produção protegendo os seus atores e o meio ambiente? Que reconheçam o ser humano como uma realidade heterogênea nas suas características físicas e culturais, mas com capacidades que permitem a convivência, isto é, todos aqueles objetivos afastados de uma filosofia que confere sentido e valor de mercadoria a tudo?

É provável que nos níveis de decisão política de nossas sociedades seja necessário manter o conceito de uma 'educação de qualidade' para continuar relacionando-se com os organismos internacionais ou concorrer aos fóruns onde são analisadas estas questões, assim como para dar legalidade às ações desenvolvidas no sistema de educação privada onde os que definem a orientação, sentido e conteúdo do conceito de 'qualidade' das suas propostas educativas são os mesmos proprietários de tais instituições privadas, de acordo com os interesses econômicos ou ideológicos próprios ou uma combinação de ambos.

Nas atuais condições econômico-sociais dos nossos países, o sistema público de ensino sempre vai estar em desvantagem em relação ao sistema 
privado enquanto se proponha utilizar a 'qualidade' no sentido que é dado pela proposta competitiva para inserir-se no mercado. As exceções que possam existir (colégios públicos de 'qualidade') só servem para confirmar a regra.

A possibilidade de elaborar uma política educacional alternativa à perspectiva economicista deve começar por diferenciar-se nos seus objetivos de formação, e essa diferenciação deve expressar-se ao nível do próprio discurso.

Uma educação que forme para a mudança social não pode ser medida como sendo de 'boa ou má qualidade', já que a sua função não está orientada a uma mera adaptação das condições sociais existentes, mas sim à busca permanente de melhoria das condições de vida da sociedade.

\section{A modo de conclusão, ainda que sem pretender concluir}

Segundo Tenti Fanfani (2008), a escola tem como objetivo influir na formação das subjetividades das novas gerações e, deste modo, prepará-las para integrar-se à sociedade no seu conjunto.

O dilema é, então, perguntar-se: quais são as subjetividades que se devem formar? De que maneira considera-se que estas novas gerações devem estar integradas à sociedade?

As respostas a estas interrogações supõem decisões no nível das políticas educativas e podem derivar de pelo menos duas matrizes teóricas: a que concebe a integração como processo destinado a manter e reproduzir as condições sociais existentes, a partir da idéia de os homens adquirirem conhecimentos e habilidades úteis para interagir com a sociedade, tornando-os mais eficientes no mundo do trabalho, no uso das novas tecnologias e nas atividades relacionadas com a legitimação da ordem política. Em outras palavras, incorporar-se à vida social, naturalizando os processos históricosociais a partir de uma perspectiva que se adapte à ordem social existente.

A outra matriz teórica é qualitativamente diferente, já que entende a integração como um processo de aquisição de saberes e habilidades para conhecer, compreender e interpretar a realidade social como resultado de um desenvolvimento histórico em que os próprios sujeitos são responsáveis pela ordem social. Nesse sentido, a integração não é uma ação meramente adaptativa, mas sim supõe situar-se em e com o mundo, incorporando os saberes necessários para poder conceber e construir relações sociais solidárias.

Ainda de acordo com Tenti Fanfani (2008), na - cada vez mais - complexa realidade social, os agentes escolares devem ter um olhar mais atento e fino do que sucede na sociedade. O conhecimento da estrutura e da lógica 
de desenvolvimento das principais dimensões da vida social é cada vez mais necessário, tanto para fazer política educativa como para exercer a ação pedagógica nas instituições e nas salas de aula.

No discurso político que predomina na maioria dos centros acadêmicos dos países capitalistas desenvolvidos, assim como nos conteúdos de muitos dos programas de organismos internacionais que promovem mudanças nos sistemas educativos nacionais, as denominações de uma 'educação de qualidade' estão mais relacionadas com a primeira perspectiva, já que foi nesse contexto onde surgiu e se constituiu o princípio que, de maneira explícita ou implícita, serviu de fundamento aos programas de organismos internacionais e serviu às políticas executivas nos países subdesenvolvidos na década de 1990.

Reformas curriculares, modelos institucionais, conteúdos para a formação docente, legislação trabalhista foram alguns dos âmbitos onde se impôs esta filosofia.

Uma perspectiva crítica das condições sociais existentes e realizadas a partir de uma proposta de educação alternativa não pode ser avaliada como de 'boa ou má qualidade' porque, na realidade, constitui uma necessidade histórica e social de nossas sociedades para romper com o colonialismo cultural e a histórica submissão aos 'paradigmas' elaborados que justificam modelos sociais que mantêm a desigualdade.

Faz-se necessário recuperar o legado das correntes sociais críticas, para poder recriar uma pedagogia que sirva para nos identificar como sociedades, nas quais ainda não alcançamos completar nossos projetos emancipatórios. É necessário recuperar as idéias de pensadores como Paulo Freire, que desnudou, faz já muitas décadas, os verdadeiros sentidos das práticas pedagógicas 'bancárias' que estavam destinadas a promover atitudes de mera adaptação ou 'integração'.

Uma educação que pretenda converter-se numa 'prática da liberdade' não é de 'boa ou má qualidade'; é, sim, o imperativo que os setores populares reclamam, principalmente os postergados, submetidos, marginalizados, excluídos, que estão nessa situação porque muitos dos que marginalizam, excluem ou submetem, receberam uma 'educação de qualidade'. 


\section{Notas}

1 Professor de Política Educacional da Universidade Nacional de Salta (UNSA), Salta, Argentina. Mestre em Educação pela Universidade Federal Fluminense (UFF). <gerbian@unsa.edu.ar>

Correspondência: Universidad Nacional de Salta, Facultad de Humanidades, Consejo de Investigación UNSa, Avenida Bolívia, 5150, Código Postal 4400, Salta, Argentina.

2 Texto, originalmente em espanhol, da conferência proferida no II Simpósio Internacional e V Fórum Nacional de Educação, realizado em maio de 2008, na Universidade Luterana do Brasil (Ulbra), Torres, Rio Grande do Sul, Brasil. Tradução de Geruza Queiroz Coutinho, da Universidade Nacional de Salta.

3 Definir como 'pós-neoliberal' a etapa histórica atual não implica afirmar que as políticas econômicas e sociais, derivadas dessas teorias, tenham sido superadas pelos governos atuais. Em alguns casos, ainda têm vigência plena. O conceito pretende fazer referência à perda da dinâmica que o neoliberalismo tem atualmente, comparado com a etapa na qual era definido como o 'pensamento único'.

4 "A comissão tinha os seguintes objetivos: 1) avaliar a qualidade do processo de ensino-aprendizagem nas escolas particulares e públicas, colleges e universidades; 2) comparar as escolas e colleges norte-americanos com outros de nações industriais mais avançados; 3) estudar as vinculações existentes entre as exigências para a admissão dos estudantes de High School e universidades e o desempenho acadêmico de quem se forma; 4) identificar programas educativos que tenham resultados exitosos notáveis em nível acadêmico e dos colleges; 5) avaliar o grau no qual as principais mudanças sociais e educativas do último quarto de século tem afetado o desempenho acadêmico dos estudantes e, finalmente, 6) definir os problemas a serem enfrentados e superados na busca da excelência da educação" (Torres, 1986).

5 "O termo provém da esfera financeira e descreve a responsabilidade das pessoas às quais o dinheiro é confiado. Isto significa informar sobre todo o desembolso de fundos, uma prestação de contas de como esses fundos foram utilizados e o que se fez com eles" (McMeekin, 2006, p. 20).

6 Na Argentina, a Lei Federal de Educação de 1993 anulou a diferença entre sistema público e sistema privado, limitando-a a uma diferença de gestão.

7 “A institucionalização de práticas políticas que apagam as diferenças entre esfera pública e esfera privada, limitando as discrepâncias à esfera privada para construir o consenso na esfera pública, dissolve a dimensão do político e oferece a imagem de uma sociedade isenta na qual desaparecem (ocultam-se) o conflito, a repressão, o poder e a violência. Interrompe uma concepção da política como eixo de transformações sociais, incorporando uma racionalidade técnica que só se expressa no plano institucional, onde prevalece a neutralidade valorativa e a eficiência das conseqüências" (Almandoz, 2005).

8 Como modelos institucionais que expressam estas tendências em educação, pode-se mencionar a escola cidadã em Porto Alegre ou as escolas charter no Chile.

9 “(...) a ciência moderna desenvolveu-se totalmente no âmbito do 'conhecimento-regulação' (CR) que recodificou, canibalizou, perverteu as possibilidades do 'conhecimento- 
emancipação' (CE). E é por isso que o CE tem que ser uma ecologia de saberes, não podendo ser simplesmente o saber moderno, científico que temos, este é importante mas tem que estar incluído numa ecologia de saberes mais ampla" (Souza Santos, 2006, p. 45).

\section{Referências}

ALMANDOZ, María Rosa. Las lógicas de las decisiones políticas en educación. In: FRIGERIO, Graciela, DICKER; Gabriela (Orgs.). Educar: ese acto político. Buenos Aires: Del Estante Editorial, 2005.

AGUERRONDO, Inés. La calidad de la educación: Ejes para su definición y evaluación. La educación. Revista Interamericana de Desarrollo Educativo, n. 116. Washington D.C.: Organização dos Estados Americanos (OEA). 1993. Disponível em <www.oei.es/ calidad2/aguerrondo.htm $>$. Acesso em: 1 maio 2008.

CASASSUS, Juan. La escuela y la (des)igualdad. Santiago: LOM Ediciones, 2003.

CORAGGIO, José Luis; TORRES, Rosa María. La Educación según el Banco Mundial. Buenos Aires: Miño y Dávila, 1997.

CORVALÁN, Javier; MCMEEKIN, Robert W. (Eds.). Accountability educacional: posibilidades y desafíos para América Latina a partir de la experiencia internacional. Santiago: Cide-Preal, 2006.

DICIONÁRIO DA REAL ACADEMIA ESPANHOLA. Versão on-line. Disponível em: <http://buscon.rae.es/draeI >. Acesso em: 1 maio 2008.

EDELMAN, Murray. La construcción del Espectáculo Politico. Buenos Aires: Manantial, 1991.

ESCUDERO, Juan Manuel. Calidad de la educación entre la seducción y las sospe- chas. Heuresis, v. 2, n. 5, 1999. Disponível em: <www2.uca.es/HEURESIS/heuresis99/ v2.html>. Acesso em: 1 maio 2008.

FELDFEBER, Myriam; SAFORCADA, Fernanda. La Educación en las cumbres de las Américas. Buenos Aires: Miño y Dávila, 2005.

GIL VILLA, Fernando. Teoría Sociológica de la Educación. Salamanca: Amarú Ediciones, 1994.

GUERRERO SERÓN, Antonio. Enseñanza y sociedad. Madri: Siglo XXI, 2003.

GIMENO SACRISTÁN, José. Los retos de la enseñanza pública. Madri: Ediciones Akal, 2001.

MARTINEZ USARRALDE, Maria Jesus. La educación en América Latina: entre la calidad y la equidad. Barcelona: Octaedro, 2005.

MCMEEKIN, Robert W. Hacia una comprensión de la accountability educativa y cómo puede aplicarse en los países de América Latina. In: CORVALÁN, Javier; MCMEEKIN, Robert W. (Eds.). Accountability educacional: posibilidades y desafíos para América Latina a partir de la experiencia internacional. Santiago: Cide-Preal, 2006, p. 19-49.

OSSENBACH SAUTER, Gabriela. Génesis de los sistemas educativos nacionales en el mundo occidental. In: ; TIANA FERRER, Alejandro; SANZ FERNÁNDEZ, 
Florentino. Historia de la Educación (Edad Contemporánea). Madri: Uned, 2005, p. 21-43.

PEDRÓ, Francesc; PUIG, Irene. Las reformas educativas. Barcelona: Paidós, 1998.

PORTELLI, Hugues. Gramsci y el bloque histórico. México D.F.: Siglo XXI, 1997.

SOUZA SANTOS, Boaventura de. Renovar la teoría crítica y reinventar la emancipación social. Buenos Aires: Clacso, 2006.

SVERDLICK, Ingrid. Buscando la calidad educativa. Crítica Educativa, ano 11, n. 2. Buenos Aires, 1997.
La evaluación universitaria. La calidad como asunto político. Revista Páginas del área educación, n. 2. Universidade Católica do Uruguai, 2001.

TENTI FANFANI, Emilio (Org.). Nuevos temas en la agenda de Política Educativa. Buenos Aires: IIPE/Siglo XXI, 2008.

TORRES, Carlos Alberto. Nation at Risk. La educación neoconservadora. In: Nueva Sociedad, n. 84. Venezuela, 1986.

TORRES, Rosa María. Itinerarios por la educación latinoamericana: cuaderno de viajes. Buenos Aires: Paidós, 2005.

Recebido em 05/06/2008

Aprovado em 26/06/2008 
